other crops. Starting in the 1920's material was accumulated systematically. Seed storage is managed in large cold chambers at $-18^{\circ} \mathrm{C}$. Seeds are kept in glass jars, covered with bags containing silica gel (active collection) and in aluminum bags under vacuum (base collection).

The maintenance of the collection requires regeneration. Each year between 8 and $10 \%$ of the collection is grown either in the field or in glasshouses. Regeneration becomes necessary when: (1) the quantity of stored seed has dropped below a pre-set threshold, due to supply to users, (2) viability falls below a pre-set threshold, (3) phenotypic evaluations of the accessions need to be conducted or (4) new accessions, which require multiplication and characterization, enter the collection. Regeneration is carried out locally to ensure genetic integrity and to minimize genetic erosion. Voucher specimens, photographs and written documentation are used to monitor the identity of the material. Special attention has to be given to out-pollinating species, which are either multiplied in small glasshouses or in isolation plots in the field.

Since the majority of genebank accessions globally are stored in the form of seed, seed longevity is of particular importance for crop germplasm preservation. At the IPK research was initiated for a range of crops stored in the genebank over decades. Variation between and within crop species was detected.

DOI $10.18699 / \mathrm{GPB} 2020-15$

\title{
Генетические механизмы ответа растений на световой стресс: реконструкция генных сетей и эволюционная перспектива
}

Бобровских А.В. ${ }^{1}$, м.н.с.; Ермаков А.А. ${ }^{l}$, м.н.с.; Зубаирова У.С. ${ }^{1}$, к.б.н., н.с.; Константинов Д.К. ${ }^{l}$, м.н.с.; Левина А.Б. ${ }^{2}$, студентка; Колодкин А.Н. ${ }^{3,4,5}$, проф.; Хейдари С. ${ }^{6}$; Дорошков А.В. ${ }^{1 *}$, к.б.н., н.с.

${ }^{1}$ ИЦиГ СО РАН, Новосибирск, Россия;

${ }^{2}$ НГУ, Новосибирск, Россия;

${ }^{3}$ Свободный Университет Амстердама, Амстердам, Нидерланды;

${ }^{4}$ Университет Амстердама, Амстердам, Нидерландь;

${ }^{5}$ Люксембургский Центр Системной Биомедицины, Университет Люксембурга, Люксембург;

${ }^{6}$ Мешхедский университет им. Фердовси, Мешхед, Иран.

*e-mail:ad@bionet.nsc.ru

Растения преобразуют энергию солнща в энергию химических связей и поэтому являются фундаментом экосистем и промышленности. Понимание того, как растения контролируют наработку биомассы, как преобразуют энергию солниа и как используют ее для создания органов и тканей 
является не только важной фундаментальной задачей, но и ключевым пунктом для дизайна новых сортов для биотехнологических систем повышенной продуктивностью. В настоящей работе проведена интеграция информации о генах, функиионально аннотированных как участники ответа на повышенную инсоляцию и дифференциально экспрессирующихся в ответ на этот стресс генов по результатам мета - анализа транскриптомных данныхx. Был проведен сравнительный анализ компонентного состава реконструированной генной сети и идентифицированы коровые компоненты сети, представленные у широкого спектра видов иветковых растений, а также компоненты, специфичные для С3 и С4 злаков.

Ключевые слова: абиотический стресс, стрессоустойчивость, световой стресс, сельское хозяйство.

\section{Genetic mechanisms of plan response to light stress: reconstruction of gene networks and evolutional prospects}

Bobrovskih A.V. ${ }^{1}$, Ermakov A.A. ${ }^{1}$, Zubairova U.S. ${ }^{1}$, Konstantinov D.K. ${ }^{l}$, Levina A.B. ${ }^{2}$, Kolodkin A.N. ${ }^{3,4,5}$, Heidari ${ }^{6}{ }^{6}$, Doroshkov A.V. ${ }^{1 *}$

${ }^{1}$ Institute of cytology and genetics SB RAS, Novosibirsk, Russia; ${ }^{2}$ Novosibirsk State University, Novosibirsk, Russia; ${ }^{3} V U$ University Amsterdam, Amsterdam, Netherlands; ${ }^{4}$ University of Amsterdam, Amsterdam, Netherlands; ${ }^{5}$ The University of Luxembourg, Luxembourg Centre for Systems Biomedicine, Luxembourg; ${ }^{6}$ Ferdowsi University of Mashhad, Mashhad, Iran.*ad@bionet.nsc.ru

Plants transform the energy of the sun into the energy of chemical bonds and therefore are the foundation of ecosystems and industry. Understanding how plants control biomass production, how they convert the energy of the sun and how to use it to create organs and tissues is not only an important fundamental task, but also a key point in the design of new varieties for biotechnological systems with increased productivity. In this work, we integrated information on genes functionally annotated as participants in a response to increased insolation and differentially expressed in response to this stress genes based on meta-analysis of transcriptome data. A comparative analysis of the component composition of the reconstructed gene network was carried out and the core components of the network represented in a wide range of flowering plant species, as well as components specific for C3 and C4 cereals, were identified.

Key words: abiotic stress, stress resistance, light stress, agriculture.

Растения - важный энергетический базис как естественных экосистем, так и множества техногенных процессов. Понимание того, как растения контролируют наработку биомассы, как преобразуют энергию солнца и как используют ее для создания органов и тканей является не только важной фундаментальной задачей, но и ключевым пунктом для дизайна новых сортов растений с повышенной продуктивностью. Установлено, что растения 
приспособлены к определенным характеристикам инсоляции и выход за их пределы (например, при дополнительным искусственным освещением растений в теплицах) быстро перестает приносить пропорциональное изменение биомассы. Одним из важнейших ограничений процессов роста и развития при повышенной инсоляции является окислительный стресс фотосинтетических тканей и недостаточная эффективность антиоксидантной системы. Так, в течение дня оптимальные характеристики фотосинтеза злаковых растений, ключевые для накопления биомассы наблюдаются в утренние и вечерние часы, тогда как в середине дня фотосинтетические ткани находятся в состоянии окислительного стресса. Математические модели, как например [1], могут служить инструментом для определения оптимальных характеристик инсоляции для работы ключевых фотозащитных механизмов растений.

Ответ на гиперинсоляцию является комплексным и затрагивает организм на разном уровне - от молекулярного до морфологического и требует системного изучения. Впервые информация о генетических механизмах была систематизирована в обзоре [2]. Авторы приводят обзор молекулярных мишеней ультрафиолетового облучения, кроме того, рассматривая молекулярные механизмы и морфологические изменение растений под действием облучения. Авторы также отмечают многофакторность действия гиперинсоляции на метаболические процессы растения и недостаточную изученность значимости отдельных факторов на устойчивость к ультрафиолетовому излучению.

Гиперинсоляция в разных зонах фотосинтетических тканей активно изучается на кукурузе Zea Mays. В статье [3] приводится анализ тканевых физиологических процессов, связанных с гипероблучением. Авторы отмечают, что гиперинсоляция уменьшает ростовую зону пластинки листа. Анализ RNAseq (GSE95858) показал, что в процесс включены факторы регуляции роста и транскрипты, участвующие в гормон-специфических путях.

Известны отдельные компоненты регуляторной сети ответа на световое облучение на модельном организме арабидопсисе. Например, в статье [4] на Arabidopsis thaliana найден один из ключевых локусов (UVR8), который является эффекторным для транскрипционного фактора НY5. Современное состояние проблемы отражает статья [5]. Обзор рассматривает фоторецептор для UVR8 [6], который активируется в ответ на продолжительное и хроническое облучение; краткосрочный ответ на UV-B излучение вызывается менее специфичными МАР-киназами [7]. Кроме того, в обзоре подробно охарактеризованы морфологические изменения растений, подвергнувшихся гиперинсоляции. В сравнении с контрольными, такие растения имеют более толстые листья, укороченные черешки и стебли, усиленное боковое ветвление и измененные пропорции корня к побегу.

Отмечается, что важную роль в передаче сигнала при ответе на гипе- 
ринсоляцию имеют активные формы кислорода, которые активируют соответствующие пути [8]. Авторы отмечают, что фоновое излучение в ходе нормального метаболизма незначительно влияет на выработку радикалов, однако стимулирует стресс, который проявляется в адаптированном измененном редокс-статусе антиоксидантов [9]. Однако серьезная гиперинсоляция вызывает повышение активных форм кислорода в фотосистемах, детектируемое на разных организмах (листья шпината, листья боба садового, листья риса). В условиях абиотического стресса концентрации активных форм кислорода модулируют активность пероксидаз, которые используют специфические субстраты для борьбы с радикалами [10]. В стрессовых условиях прекращаются ростовые процессы, а при возвращении уровня радикалов в пределы нормы происходит восстановление роста.

В настоящей работе проведен мета анализ транскриптомных данных ответа на гиперинсоляцию с выявлением перспективных генов-кандидатов. Найденные гены были интегрированы с известными генетическими регуляторными компонентами ответа на световой стресс у A. thaliana. Реконструированная генная сеть состоит из 104 известных генов и обогащена 245 новыми генами. Были обнаружены ранее не описанные блоки, связанные с процессингом рибосомальных РНК (16 генов), регуляцией жасмонатного сигнального пути (5), протеосомальным катаболизмом (7), ионным транспортом (10), а также наличие в сети серии глутатион S-трансфераз, которые способны за счет восстановленного глутатиона осуществлять регенерацию липоперекисей в мембранах, снижая последствия окислительного стресса. Прицельное усиление активности антиоксидантной системы является перспективным путем снижения нагрузки на фотосинтетические ткани и, таким образом, увеличения периода эффективной аккумуляции энергии, что позволит сократить период вегетации и сделать возделывание злаковых растений в условиях рискованного земледелия более эффективным.

При помощи подходов сравнительной геномики, мета анализа транскриптомных данных и подходов молекулярной филогении нами были сопоставлены реконструированные и расширенные сети ответа на световой стресс между A. thaliana, Zea mays, Oryza sativa, Hordeum vulgare u Triticum aestivum. Были идентифицированы коровые компоненты сети, представленные у широкого спектра видов цветковых растений, а также компоненты, специфичные для С3 и С4 злаков.

Благодарности: Исследование выполнено при финансовой поддержке РФФИ и Правительства Новосибирской области в рамках научного проекта № 19-44-543021.

\section{Список литературы}

1. Matuszyńska, A., Heidari, S., Jahns, P., Ebenhoeh, O. (2016). A mathematical model of non-photochemical quenching to study short-term light memory in plants. Biochimica et Biophysica Acta (BBA)-Bioenergetics, 1857(12), 1860-1869. 
2. Jansen, M.A., Gaba, V., Greenberg, B.M. (1998). Higher plants and UV-B radiation: balancing damage, repair and acclimation. Trends in plant science, 3(4), 131-135.

3. Fina, J., Casadevall, R., AbdElgawad, H., Prinsen, E., Markakis, M. N., Beemster, G. T., \& Casati, P. (2017). UV-B inhibits leaf growth through changes in growth regulating factors and gibberellin levels. Plant physiology, 174(2), 1110-1126.

4. Brown, B.A., Cloix, C., Jiang, G.H., Kaiserli, E., Herzyk, P., Kliebenstein, D.J., Jenkins, G.I. (2005). A UV-B-specific signaling component orchestrates plant UV protection. Proceedings of the National Academy of Sciences, 102(50), 1822518230.

5. Robson, T.M., Klem, K., Urban, O., \& Jansen, M.A. (2015). Re-interpreting plant morphological responses to UV-B radiation. Plant, cell \& environment, 38(5), 856-866.

6. Rizzini, L., Favory, J. J., Cloix, C., Faggionato, D., O’Hara, A., Kaiserli, E., ... \& Ulm, R. (2011). Perception of UV-B by the Arabidopsis UVR8 protein. Science, 332(6025), 103-106.

7. González Besteiro, M. A., Bartels, S., Albert, A., \& Ulm, R. (2011). Arabidopsis MAP kinase phosphatase 1 and its target MAP kinases 3 and 6 antagonistically determine UV-B stress tolerance, independent of the UVR8 photoreceptor pathway. The Plant Journal, 68(4), 727-737.

8. Hideg, É., Jansen, M. A., \& Strid, Å. (2013). UV-B exposure, ROS, and stress: inseparable companions or loosely linked associates?. Trends in plant science, 18(2), $107-115$.

9. Heuberger, H., Praeger, U., Georgi, M., Schirrmacher, G., Grasmann, J., \& Schnitzler, W.H. (2004, March). Precision stressing by UV-B radiation to improve quality of spinach under protected cultivation. In VII International Symposium on Protected Cultivation in Mild Winter Climates: Production, Pest Management and Global Competition 659 (pp. 201-206).

10. Tenhaken, R. (2015). Cell wall remodeling under abiotic stress. Frontiers in plant science, 5,771 .

DOI 10.18699/GPB2020-16

\section{Реконструкция регуляторных генных сетей ответа на солевой стресс Arabidopsis thaliana и Zea mays}

Бобровских А.В. ${ }^{l}$, м.н.с.; Ермаков А.А. ${ }^{l *}$, м.н.с.; Зубаирова У.С. ${ }^{1}$, к.б.н., н.с.; Константинов Д.К. ${ }^{\text {, }, ~ м . н . с . ; ~ Л е в и н а ~ А . Б . ~}{ }^{2}$, студентка; Дорошков А.В. ${ }^{l}$, к.б.н., H.c.

${ }^{1}$ ИЦиГ СО РАН, Новосибирск, Россия;

${ }^{2}$ НГУ, Новосибирск, Россия;

*e-mail:ermakov@bionet.nsc.ru

Засоление является одним из важнейших абиотических факторов, ограничивающих зоны возделывания сельскохозяйственных культур. Ответ 